\title{
IMMUNOHISTOCHEMICAL STUDY OF ENTERIC NERVOUS SYSTEM IN DEXAMETHASONE-TREATED RATS
}

\author{
Radmila M. Glišićc ${ }^{*}$, Maja M. Čakić-Milošević², Mirela M. Ukropina² \\ University of Kragujevac, Faculty of Science, Department of Biology and Ecology, \\ Radoja Domanovića 12, PO Box 60, 34000 Kragujevac, Republic of Serbia \\ ${ }^{2}$ University of Belgrade, Faculty of Biology, Institute of Zoology, \\ Studentski trg 16, 11000 Belgrade, Republic of Serbia \\ *Corresponding author; E-mail: rada@kg.ac.rs
}

(Received February 22, 2018; Accepted March 12, 2018)

\begin{abstract}
The gut is supplied with its own nervous system, referred to as the enteric nervous system (ENS). It regulates the various functions of a digestive system such as motility, secretion and digestion and has close interactions with the enteric immune system. The aim of this study was to investigate the alterations of the ENS in dexamethasone-treated rats using two general neuroendocrine markers: protein gene product 9.5 (PGP 9.5) and synaptophysin (SY). As concluded from the changes in a pattern of immunoexpression of the markers applied, some remodeling of the ENS occured. Further investigations are needed to elucidate in more details its nature and importance with respect to gastrointestinal complications seen in diabetes.
\end{abstract}

Keywords: enteric nervous system, dexamethasone, rat.

\section{INTRODUCTION}

The neuroendocrine system of the gut is its regulatory system consisting of enteroendocrine cells scattered among the epithelial cells and the neurons and nerve fascicles of the enteric nervous system (ENS), forming a neural network embedded in the wall of the gastrointestinal tract (GIT). The functional classes of enteric neurons are sensory neurons involved in monitoring of the conditions in the gut, interneurons, which integrate this information and motor neurons, either stimulatory or inhibitory, that control motility, secretion and digestion in the gut. In addition, the ENS contains glial cells as well as interstitial cells of Cajal (COSTA et al., 2000; NEZAMI and SRINIVASAN, 2010). The most of the enteric nerve cells are arranged into two mutually interconnected nerve plexuses: myenteric (Auerbach's) and submucosal (Meissner's).

The myenteric plexus is located between the two muscle layers of muscularis externa and is involved in the regulation of relaxation and contraction of the intestinal wall (FURNESS and COSTA, 1987). Its ganglia and interconnecting nerve fibers form a polygonal network (SMiTH, 1970). The nerve fibers are divided into primary, secondary and tertiary, where first two are interganglionic, and the latter are ramified into the adjacent muscle layers. In both muscle layers, an aganglionated plexus exists in a form of a dense network of fine nerve fibers oriented parallel to the course of the corresponding smooth muscle cells (WEDEL et al., 1999). 
The ganglia of the submucosal plexus are composed of a densely packed neuron bodies, that are surrounded by glial cells and terminal bundles made up of nerve fibers (GUlBRANSEN, 2014). The neurons of the submucosal plexus innervate glandular epithelium, muscularis mucosae, intestinal endocrine cells and submucosal blood vessels and are involved in the regulation of mucosal blood flow and epithelial cells function, as well as in the detection of nutrients in the enteric lumen (SANOOP et al., 2012; NEUNLIST and SCHEMANN, 2014).

The ENS acts independently of the central nervous system (CNS) (GOYAL and HIRANO, 1996) and can be considered as the third component of the autonomic nervous system. It acts through local reflexes (FURNESS et al., 1995) and interactions with the autonomous system (FURNESS et al., 2014) and endocrine cells of the tract itself (SCHUTTE et al., 1997; FURNESS, 2016). In addition to the mentioned functions, the ENS is also involved in the regulation of immune and inflammatory processes in the gut (COOKE, 1994).

The enteric neurons perform their activities through more than 25 neurotransmitters (in most neurons several of them being colocalized), such as acetylcholine, serotonin, gastrin, VIP, NO, NPY, galanin, ATP, GABA etc. (GERSHON et al., 1994; MCCONALAGUE and FURNESS, 1994; SONG et al., 1997).

Diabetes mellitus is a disease that causes damage in almost all of the organic systems of animals and humans, leading to numerous and serious health complications. Bearing in mind the role of the ENS in the control of the GIT function, it can be assumed that gastrointestinal symptoms common in patients with diabetes mellitus, such as nausea, vomiting, diarrhea, abdominal pain and constipation (FELDMAN and SCHILLER, 1983; BYTZER et al. 2001) might be associated with disturbances of the ENS (EL-SALHY, 2006).

For that reason, the aim of this study was to investigate an alteration in the intensity of the gut wall innervation by ENS in dexamethasone-treated rats, as an experimental model of a prediabetic stage/diabetes mellitus type 2 (MULDER, 1997). The innervation of the gut wall was assessed on the basis of the immunoexpression of the protein gene product 9.5 (PGP 9.5) and synaptophysin (SY) as general markers of neurons and neuroendocrine cells (THOMPSON et al., 1983; CALAKOS and SCHELLER, 1994).

\section{MATERIALS AND METHODS}

\section{Animals and tissue preparation}

Twenty male Wistar rats (obtained from the vivarium of the Vinča Institute of Nuclear Sciences, Belgrade, Republic of Serbia) aged 30 days were kept in standardized laboratory conditions (a $12 / 12 \mathrm{~h} \mathrm{light/dark}$ cycle at $22^{\circ} \mathrm{C}$ ), in metabolic cages. A standard laboratory rat chow diet and tap water were available ad libitum. The animals were randomly allocated into the control (C, 10 rats) and dexamethasone-treated (D, 10 rats) groups. The animals of the group D were injected with dexamethasone dissolved in the saline $\left(2 \mathrm{mg} \mathrm{kg}^{-1}\right.$, i.p. during 12 days) while the rats of the group $\mathrm{C}$ received the saline only. After the experimental period, the animals were fasted overnight and sacrificed in a light ether anesthesia. This protocol was approved by the Serbian Animal Use Committee. The experiment was performed according to the rules of animal care proposed by the Serbian Laboratory Animal Science Association.

\section{Preparation of histological sections for immunohistochemistry}

The tissue specimens (different parts of the gut - jejunum, ileum, caecum and colon) from all the animals were fixed in Bouin's fluid, embedded in paraffin and cut into $5 \mu \mathrm{m}$ thick sections. The immunohistochemical examination of the ENS was performed using two 
markers - PGP 9.5 and SY. The immunohistochemistry was carried out by the streptavidinbiotin immunoperoxidase technique (LSAB+/HRP kit, Dako, Carpinteria, CA) using the antisera against SY (diluted 1:50, overnight incubation at $4^{\circ} \mathrm{C}$; Dako, Carpinteria, CA, Code No. A0010) and PGP 9.5 (diluted 1:25, overnight incubation at $4^{\circ} \mathrm{C}$; Dako, Carpinteria, CA, Code No. Z5116), following the manufacturer's recommendations. Visualisation of reaction sites was done by AEC Substrate Chromogen. The sections were then counterstained with hematoxylin. The analysis was performed on the Olympus light microscope at an objective magnification of $x 20$. The intensity of immunoexpression was semiquantified independently by three observers and presented as strong $(+++)$, moderate $(++)$, weak $(+)$ or no reaction $(-)$.

\section{RESULTS}

The results obtained for the immunoexpression of PGP 9.5 and SY are shown in Table 1.

Table 1. Evidence on PGP 9.5- and SY-immunoreactivity in different parts of GIT

\begin{tabular}{|c|c|c|c|c|c|c|c|c|}
\hline \multirow{3}{*}{ Region } & \multicolumn{4}{|c|}{ PGP 9.5} & \multicolumn{4}{|c|}{$S Y$} \\
\hline & \multicolumn{2}{|c|}{$\mathbf{C}$} & \multicolumn{2}{|c|}{ D } & \multicolumn{2}{|c|}{$\mathbf{C}$} & \multicolumn{2}{|c|}{ D } \\
\hline & $\mathbf{S}$ & $\mathbf{M}$ & $\mathbf{S}$ & $\mathbf{M}$ & $\mathbf{S}$ & $\mathbf{M}$ & $\mathbf{S}$ & $\mathbf{M}$ \\
\hline Jejunum & + & ++ & ++ & +++ & + & ++ & - & +++ \\
\hline Ileum & $+/++$ & +++ & $++/+++$ & +++ & $+/++$ & +++ & ++ & +++ \\
\hline Caecum & + & ++ & + & +++ & - & $+/++$ & + & ++ \\
\hline Colon & + & +++ & + & +++ & ++ & ++ & ++ & +++ \\
\hline
\end{tabular}

+++ strong, ++ moderate, + weak, - negative;

$\mathrm{S}$ - submucosal plexus, $\mathrm{M}$ - myenteric plexus

\section{The immunoreactivity to PGP 9.5}

In both jejunal plexuses (submucosal and myenteric) of animals from the $\mathrm{D}$ group, the PGP 9.5 immunoexpression was stronger than in the $\mathrm{C}$ group (Fig. 1a, b), being particularly prominent in the myenteric plexus. In the ileum, the pattern of immunoexpression was generally similar (Fig. 1c, d). In the myenteric plexus of the caecum, reaction was stronger after treatment with dexamethasone (Fig. 1e, f). In the colon, there was no difference in the intensity of reaction between the groups (Fig. 1g, h). Overall, a stronger PGP 9.5immunoreactivity was recorded in the examined regions of the gut of dexamethasone-treated animals, as compared to the control. In both groups, the part of the gut that showed the most prominent reaction was the ileum. In all animals studied, the strongest reaction was at the level of the myenteric plexus.

\section{The immunoreactivity to $S Y$}

In the myenteric plexus of the jejunum of the dexamethasone-treated rats, SY immunoreaction was stronger than in the control group, but it was absent in submucosal plexus, as opposed to controls with a weak reaction (Fig. 2a, b). In the ileum, the pattern of SY immunoexpression was generally similar in both groups of animals, with the stronger reaction in the myenteric plexus (Fig. 2c, d). In the caecum, a relatively low level of reaction was observed in both groups of rats, with complete absence of immunostaining in the submucosal plexus of the control (Fig. 2e, f). On the contrary, the SY immunoexpression in the colon of both control and dexamethasone-treated animals was generally at the high level 
(Fig. 2g, h). Overall, the immunoreactivity to SY was most prominent in the myenteric plexus, in both groups of animals.

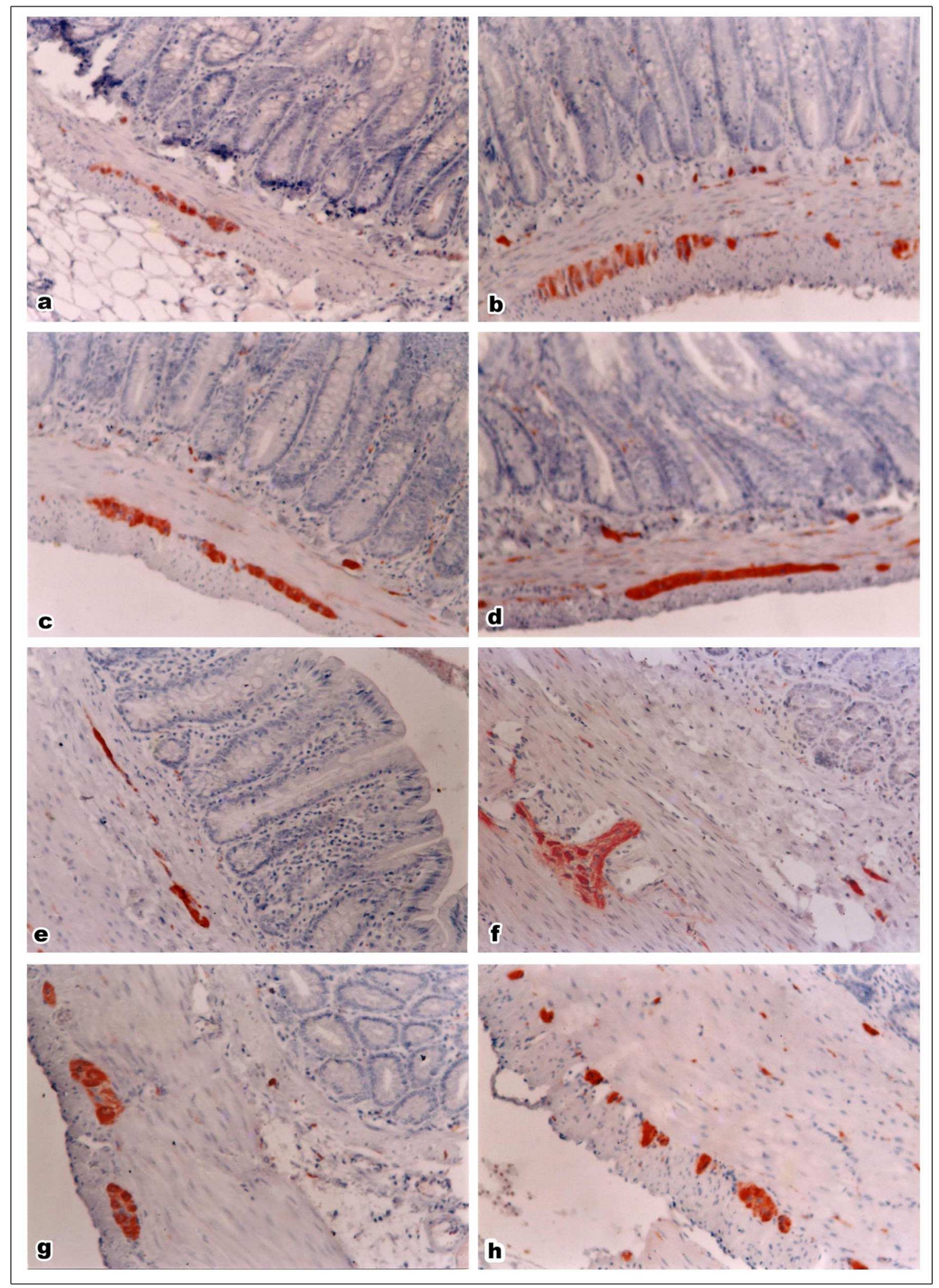

Figure 1. PGP 9.5-immunoreactivity in different parts of the gut in tha control (C) and dexamethasone-treated (D) rats: a) jejunum - $\mathrm{C}$ rat, b) jejunum $-\mathrm{D}$ rat; c) ileum - $\mathrm{C}$ rat, d) ileum - D rat; e) caecum - C rat, f) caecum - D rat; g) colon - C rat, h) colon - D rat. x 20 


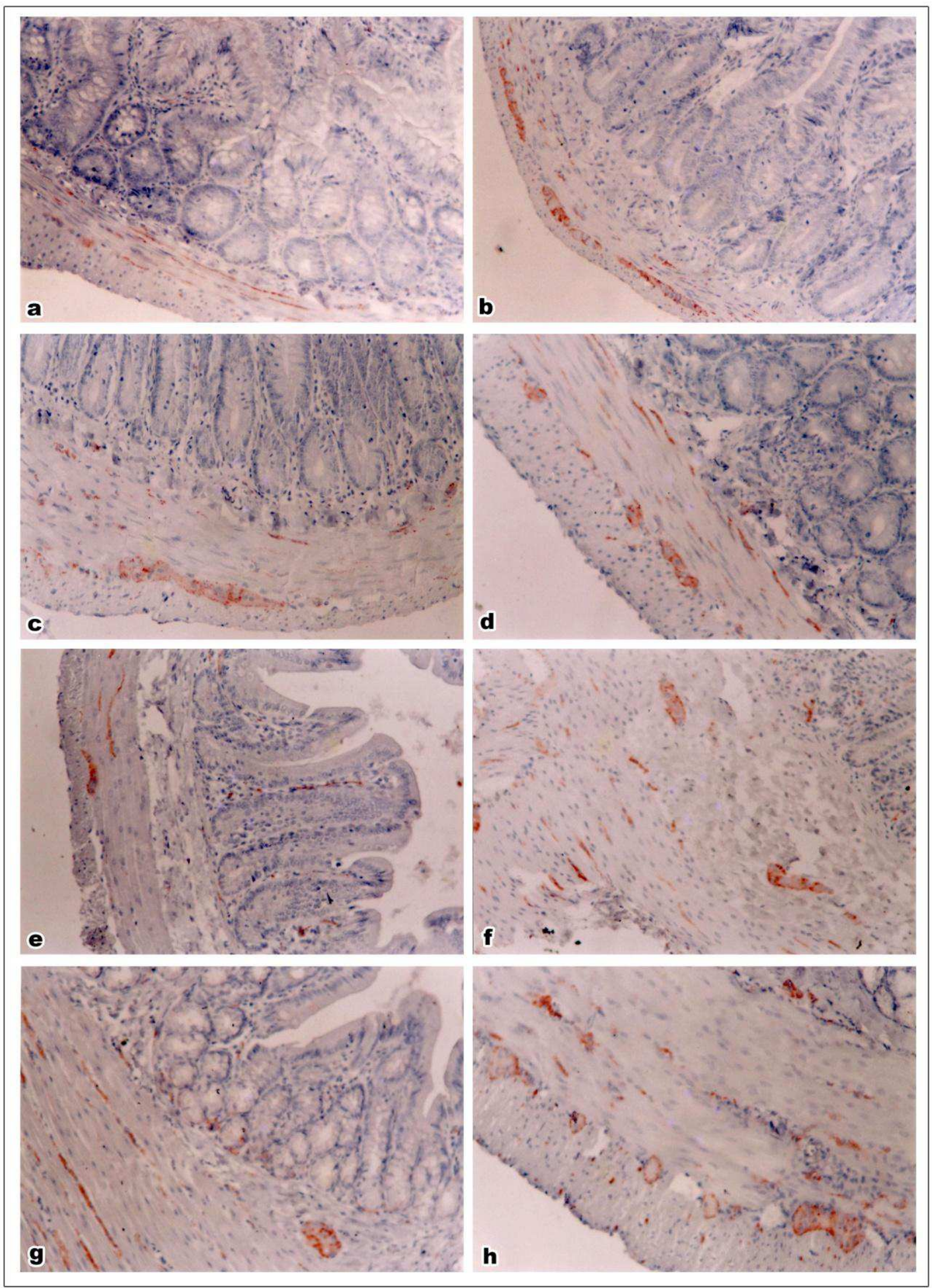

Figure 2. SY-immunoreactivity in different parts of the gut in the control (C) and dexamethasonetreated (D) rats. a) jejunum - C rat, b) jejunum - D rat; c) ileum - C rat, d) ileum - D rat; e) caecum $\mathrm{C}$ rat, f) caecum - D rat; g) colon $-\mathrm{C}$ rat, h) colon - D rat. x 20 


\section{DISCUSSION}

The dexamethasone is a synthetic glucocorticoid frequently used in the therapy of different diseases and conditions including inflammation, bacterial infections, autoimmune diseases, graft versus host disease and even in some forms of cancer (CoOK et al., 2016). Unfortunately, the dexamethasone treatment is usually associated with undesirable sideeffects, some of which might be serious as the primary disease itself. Previous studies, evaluating effects of the dexamethasone in humans and animals, reported a strong relationship between its use and impaired glucose homeostasis (PAQUOT et al., 1995; KWON and HERMAYER, 2013), which after a prolonged treatment can lead to the development of diabetes mellitus type 2 (OGAWA et al., 1992). Thus, this side-effect makes dexamethasone suitable for use as a diabetogenic agent in different animal models of diabetes (MULDER, 1997; KING, 2012).

Given that gastrointestinal disorders involving motility impairment are relatively common in diabetic patients, this study (as a part of the wider research) was designed to investigate the alterations in the intensity of the ENS innervation of defined regions of small and large intestine, using animal model of dexamethasone-induced prediabetes/diabetes type 2 (MULDER, 1997). Based on the previously reported results (KOKO et al., 2001; GLIŠIĆ et al., 2006), which emerged from the above-mentioned comprehensive research, we already showed that same treatment caused hypoglycemia, glycosuria, increase in plasma and pancreatic insulin levels, as well as the strong hypertrophy and hyperplasia of the pancreatic B cells, together indicating the impaired glucose tolerance and diabetic state.

In order to visualize the ENS elements, we used the immunohistochemical expression of PGP 9.5 and SY as markers (LUNDBERG et al., 1988; CALAKOS and SCHELLER, 1994). Otherwise, the topography and structure of the ENS were investigated in the past mainly using a silver impregnation (KUMAR and PHILLIPS, 1989) and whole mount immunohistochemistry with antibodies against the PGP 9.5 (KRAMMER et al., 1993; WEDEL et al., 1999). The expression of the SY as an integral membrane glycoprotein located on presynaptic vesicles was used for the evaluation of a nerve degeneration or regeneration (OKAJIMA et al., 2000; LI et al., 2010), as a marker for the synaptic density.

The results of this study showed a rather uniform expression of the PGP 9.5 along the investigated gut regions of untreated rats, with only slightly stronger reaction in the myenteric plexus of the ileum and colon. The dexamethasone treatment induced the increase of PGP 9.5immunoreaction in submucosal plexus of jejunum and ileum, and in myenteric plexus of jejunum and cecum. Thus, after the dexamethasone treatment, the total PGP 9.5immunoreactivity was stronger than in the control rats. Also, the immunoreactivity was stronger in the segments of the small intestine than in those of the large intestine. In respect to the SY-immunoreactivity in the control animals, it varied along the intestinal segments, being mainly stronger in the myenteric plexus of all segments. The treatment with dexamethasone mainly caused the increase of immunoreactivity, except in the submucosal plexus of the jejunum.

In general, the dexamethasone treatment induced increase in the PGP 9.5- and SYimmunoreactivity in nerve plexuses of intestine regions studied. The increase in the PGP 9.5immunoreactivity in some parts of the intestine wall could indicate proliferation of neural elements (Lundberg et al., 1988). Similarly, SY expression as a marker for synaptic density (MASLIAH et al., 1990), an increase in the SY-immunoreactivity may suggest a regeneration of neurons and consequently more intensive synaptic transmission (DZIENIS-KORONKIEWICZ et al., 2005).

The more intensive innervation of the intestine wall by the ENS, observed in the animal model of prediabetes/diabetes type 2 used in the present study, may cause more or less 
inappropriate activity of the intestine in food processing, such as accentuated secretion, absorption and motility (peristaltic wave). We believe that such changes might lead to digestive disturbances expected to be the most pronounced at the jejunal level, where the most of the food absorption takes place.

In relation to the ENS in diabetes, it is known that changes exist in the enteric neuronal size, number (ZANONI at al., 1997; FURLAN et al., 2002) and morphology (axonal swelling) as well as in the neurotransmitter expression (SPÅNGÉUs et al., 2000; CHANDRASEKHARAN and SRINIVASAN, 2007). It seems that in the initial phase of diabetes there is a loss of neurons, after which the regenerative phase follows (ADEGHATE et al., 2003). Generally, diabetes is associated with the loss of inhibitory neurons and the increase in excitatory neurons (HE et al., 2001; IWASAKI et al., 2006).

The dexamethasone-treated animals in the present study, developed diabetes similar to human diabetes mellitus type 2 (GLIŠIĆ et al., 2006) and changes in the enteric innervation occurred, likely in the direction to neuronal regeneration. This is consistent with the literature data (ADEGHATE et al., 2003; ChANDRASEKHARAN and SRINIVASAN, 2007). It could be a compensatory response to a loss of some type of enteric neurons after the applied treatment.

Generally, the observed changes in the number, density and ultrastructure of the gut endocrine cells in our previous reports (KOKO et al., 2001; GLIŠIĆ et al., 2006; KоKO et al., 2008; GLIŠIĆ et al., 2011) as well as the changes in the ENS in the dexamethasone-treated rats, presented in this study, indicate a likely disturbed bowel motility and secretion. The disturbance of the gut motility and secretion interfere with normal metabolic processes of food digestion, which may lead to impaired glucose homeostasis and the development of other symptoms and complications of diabetes mellitus type 2.

\section{CONCLUSIONS}

The evidences obtained from this study showed that the dexamethasone treatment induced changes in the intensity of the ENS innervation of the gut wall, which may be related to digestive dysfunctions commonly seen in diabetes. However, further investigations are needed to elucidate in more details the nature of observed alterations of ENS.

\section{Acknowledgments}

This work was performed in the Institute for Medical Research in Belgrade. Thanks are due to Prof. Vesna Koko for her great contribution to organization and realization of the experiment, analysis and discussion of the results obtained and to Mrs. Leposava Jovanović for her excellent technical assistance as well as to Vesna Glišić for proofreading of the text.

\section{References:}

[1] Adeghate, E., Al-Ramadi, B., Saleh, A.M., Vijayarasathy, C., Ponery, A.S., ARAFAT, K., HOWARTH, F.C., El-SHARKAWY, T. (2003) Increase in neuronal nitric oxide synthase content of the gastroduodenal tract of diabetic rats. Cellular and Molecular Life Sciences 60 (6): 1172-1179. doi: 10.1007/s00018-003-2298-2

[2] Bytzer, P., Talley, N.J, Leemon, M., Young, L.J., Jones, M.P., Horowitz, M. (2001): Prevalence of gastrointestinal symptoms associated with diabetes mellitus: a 
population-based survey of 15,000 adults. Archives of internal medicine 161 (16): 19891996. doi: 10.1001/archinte.161.16.1989

[3] Calakos, N., SchelleR, R.H. (1994): Vesicle-associated membrane protein and synaptophysin are associated on the synaptic vesicle. Journal of Biological Chemistry 269 (40): 24534-7. http://www.jbc.org/content/269/40/24534.abstract Accessed 27 May 2018.

[4] Chandrasekharan, B., Srinivasan, S. (2007): Diabetes and the enteric nervous system. Neurogastroenterology and Motility 19 (12): 951-960. doi: 10.1111/j.13652982.2007.01023.x

[5] CooK, M.A., McDonnell, M.A., LAKe, A.R., NowaK, K.A. (2016): Dexamethasone co-medication in cancer patients undergoing chemotherapy causes substantial immunomodulatory effects with implications for chemo-immunotherapy strategies. Oncoimmunology 5 (3): e1066062. doi: 10.1080/2162402X.2015.1066062

[6] COOKE, H.J. (1994): Neuroimmune signaling in regulation of intestinal ion transport. American Journal of Physiology 266 (2): G167-78. doi: 10.1152/ajpgi.1994.266.2.G167

[7] Costa, M., Brookes, S.J.H., Hennig, G.W. (2000): Anatomy and physiology of the enteric nervous system. Gut (Suppl IV) 47: iv15-iv19. doi: 10.1136/gut.47.suppl_4.iv15

[8] Dzienis-Koronkiewicz, E., Debek, W., Chyczewski, L. (2005): Use of synaptophysin immunohistochemistry in intestinal motility disorders. European Journal of Pediatric Surgery 15 (6): 392-398. doi: 10.1055/s-2005-872949

[9] El-Salhy, M. (2006): Gut neuroendocrine system in diabetes gastroenteropathy: possible role in pathophysiology and clinical implications. In: Ashley M. Ford (ed.) Focus on Diabetes Mellitus Research, Chapter V. Nova Biomedical Books, New York, pp. 79-102.

[10] FELdMAN, M., SCHILlER, L.R. (1983): Disorders of gastrointestinal motility associated with diabetes mellitus. Annals of internal medicine 98 (3): 378-384. doi: 10.7326/00034819-98-3-378

[11] Furlan, M.M.D.P., Molinari, S.L., DE Miranda Neto, M.H. (2002): Morphoquantitative effects of acute diabetes on the myenteric neurons of the proximal colon of adult rats. Arquivos de Neuro-Psiquiatria 60 (3-A): 576-581. doi: 10.1590/S0004-282X2002000400012

[12] FURNESS, J.B. (2016): Integrated neural and endocrine control of gastrointestinal function. Advances in Experimental Medicine and Biology 891: 159-173. doi: 10.1007/978-3-319-27592-5_16

[13] Furness, J.B., Callaghan, B.P., Rivera, L.R, ChO, H.J. (2014): The enteric nervous system and gastrointestinal innervation: integrated local and central control. Advances in Experimental Medicine and Biology 817: 39-71. doi: 10.1007/978-1-4939-0897-4_3

[14] Furness, J.B., Costa, M. (1987): The enteric nervous system. Churchill Livingstone, Edinburgh.

[15] Furness, J.B., Johnson, P.J., Pomolo, S., Bornstein, J.C. (1995): Evidence that enteric motility reflexes can be initiated through entirely intrinsic mechanisms in the guinea-pig small intestine. Neurogastroenterology and motility 7 (2): 89-96. doi: 10.1111/j.1365-2982.1995.tb00213.x/ 
[16] Gershon, M.D., Kirchgessner, A.L., Wade, P.R. (1994): Functional anatomy of the enteric nervous system. In: Johnson, L.R. (ed.) Physiology of the gastrointestinal tract. 3rd edition. New York, Raven Press, pp. 381-422.

[17] Glišić, R., Koko, V., Todorović, V., Drndarević, N., CviJić, G. (2006): Serotoninproducing enterochromaffin (EC) cells of gastrointestinal mucosa in dexamethasonetreated rats. Regulatory Peptides 136 (1-3): 30-39. doi: 10.1016/j.regpep.2006.04.019

[18] Glišić, R., KoKo, V., CviJiĆ, G., ČAKiĆ-MilošEvić, M., Obradović, J. (2011): Cholecystokinin-producing (I) cells of intestinal mucosa in dexamethasone-treated rats. Regulatory Peptides 171 (1-3): 6-10. doi: 10.1016/j.regpep.2011.05.012

[19] Goyal, R.K., HIRANO, I. (1996): The enteric nervous system. The New England journal of medicine 334 (17): 1106-1115. doi: 10.1056/NEJM199604253341707

[20] GulbRAnSEN D.B. (2014): Enteric Glia. Colloquium series on neuroglia in biology and medicine: from physiology to disease. In: Verkhratsky, A., Vladimir Parpura, V. (eds) Colloquium Digital Library of Life Sciences. Morgan \& Claypool, Life Sciences.

[21] He, C.L., Soffer, E.E., Ferris, C.D., WAlsh, R.M., Szurszewski, J.H., FArrugia, G. (2001): Loss of interstitial cells of Cajal and inhibitory innervation in insulin-dependent diabetes. Gastroenterology 121 (2): 427-434. doi: 10.1053/gast.2001.26264

[22] Iwasaki, H., Kajimura, M., Osawa, S., Kanaoka, S., Furuta, T., Ikuma, M., HISHIDA, A. (2006): A deficiency of gastric interstitial cells of Cajal accompanied by decreased expression of neuronal nitric oxide synthase and substance $\mathrm{P}$ in patients with type 2 diabetes mellitus. J Gastroenterol 41 (11): 1076-1087. doi: 10.1007/s00535-006$1909-8$

[23] KING, A.J. (2012): The use of animal models in diabetes research. Br J Pharmacol 166 (3): 877-894. doi: 10.1111/j.1476-5381.2012.01911.x

[24] Koko, V., Glišić, R., Todorović, V., Drndarević, N., Mitrović, O. (2008): Glucosedependent insulinotropic polypeptide producing $-\mathrm{K}$ cells in dexamethasone-treated rats. Journal of Microscopy, 232 (Pt 3): 493-497. doi: 10.1111/j.1365-2818.2008.02146.x

[25] Koko, V., Todorović, V., Glišić, R., Nikolić, A. (2001): $\beta$-cells in dexamethasone treated rats. Archive of Oncology (Serbia) 9 (Suppl 1): 42.

http://www.onk.ns.ac.rs/archive/Vol9/PDFVo19/V9S1-3-Extended-Abstracts.pdf Accessed 27 May 2018.

[26] Krammer, H.J., Karahan, S.T., Rumpel, E., Klinger, M., Kühnel, W. (1993): Immunohistochemical visualization of the enteric nervous system using antibodies against protein gene product (PGP) 9.5. Ann Anat 175 (4): 321-325.

doi: 10.1016/S0940-9602(11)80029-4

[27] Kumar, D., PhiLliPS, S.F. (1989): Human myenteric plexus: confirmation of unfamiliar structures in adults and neonates. Gastroenterology 96 (4): 1021-1028. doi: 10.1016/0016-5085(89)91619-3

[28] KwOn, S., Hermayer, K.L. (2013): Glucocorticoid-induced hyperglycemia. Am. J. Med. Sci 345 (4): 274-277. doi: 10.1097/MAJ.0b013e31828a6a01

[29] LI, C., LIU, S., GUAN Y., QIAN, W., DU, F., HoU, X. (2010): Long pulse gastric electrical stimulation induces regeneration of myenteric plexus synaptic vesicles in diabetic rats. Neurogastroenterology \& Motility 22 (4): 453-461.

doi: 10.1111/j.1365-2982.2009.01420.x 
[30] Lundberg, L.-M., Alm, P., Wharton, J., PolaK, J.M. (1988): Protein gene product 9.5 (PGP 9.5). A new neuronal marker visualizing the whole uterine innervation and pregnancy-induced and developmental changes in the guinea pig. Histochemistry 90 (1): 9-17. doi: 10.1007/BF00495700

[31] Masliah, E., Terry, R.D., Alford, M., DeTeresa, R. (1990): Quantitative immunohistochemistry of synaptophysin in human neocortex: an alternative method to estimate density of presynaptic terminals in paraffin sections. Journal of Histochemistry \& Cytochemistry 38 (6): 837-844. doi: 10.1177/38.6.2110586

[32] McConalague, K., FuRness, J.B. (1994): Gastrointestinal neurotransmitters. Baillière's Clinical Endocrinology and Metabolism 8 (1): 51-76. doi: 10.1016/S0950351X(05)80226-5

[33] Mulder, H. (1997): Expression of islet amyloid polypeptide. Localization and regulation in the pancreatic islets, gastrointestinal tract and sensory nervous system. PhD thesis, Department of Experimental Medical Science, Neurogastroenterology Lund University, Lund.

[34] Neunlist, M., Schemann, M. (2014): Nutrient-induced changes in the phenotype and function of the enteric nervous system. The Journal of Physiology 592 (14): 2959-2965. doi: 10.1113/jphysiol.2014.272948

[35] NeZami, B.G., SRinivasan, S. (2010): Enteric nervous system in the small intestine: pathophysiology and clinical implications. Current Gastroenterology Reports 12 (5): 358-365. doi: 10.1007/s11894-010-0129-9

[36] Ogawa, A., Johnson, J.H., Ohneda, M., McAllister, C.T., Inman, L., Alam, T., UNGER, R.H. (1992): Roles of insulin resistance and $\beta$-cell dysfunction in dexamethasone-induced diabetes. The Journal of Clinical Investigation 90 (2): 497-504. doi: 10.1172/JCI115886

[37] OKAJIMA, S., SHIRASU, M., HiRASAWA, Y., IDE, C. (2000): Ultrastructural characteristics and synaptophysin immunohistochemistry of regenerating nerve growth cones following traumatic injury to rat peripheral nerve. The Journal of Reconstructive Microsurgery 16 (8): 637-642. doi: 10.1055/s-2000-9382

[38] Paquot, N., Schneiter, P., JÉQuier, E., TAPPy, L. (1995): Effects of glucocorticoids and sympathomimetic agents on basal and insulin-stimulated glucose metabolism. Clinical Physiology 15 (3): 231-240. doi: 10.1111/j.1475-097X.1995.tb00514.x

[39] Sanoop, K.S., Mridul, G.S., Nishanth, P.S. (2012): Gastrointestinal system. In: Swarnalatha, P.K. (ed). Physicon - The Reliable Icon in Physiology. Preparatory manual for undergraduates. Chapter 5. Jaypee Brothers Medical Publishers (P) Ltd. New Delhi, Panama City, London, pp. 92-93.

[40] Schutte, I.W., Akkermans, L.M., Kroese, A.B. (1997): CCKA and CCKB receptor subtypes both mediate the effects of CCK-8 on myenteric neurons in the guinea-pig ileum. Journal of the Autonomic Nervous System 67 (1-2): 51-59. doi: 10.1016/S01651838(97)00092-1

[41] Sмiтh, B. (1970): Disorders of myenteric plexus. Gut 11 (3): 271-274. doi: 10.1136/gut.11.3.271

[42] Song, Z., Brookes, M., Ramsey, G.A., Costa, M. (1997): Characterization of myenteric interneurons with somatostatin immunoreactivity in the guinea/pig small intestine. Neuroscience 80 (3): 907-923. doi: 10.1016/S0306-4522(96)00605-7 
[43] SpÅngéus A, SuHR O, El-SAlHy M. (2000): Diabetic state affects the innervation of gut in an animal model of human type 1 diabetes. Histology and Histopathology 15: 739744. doi: 10.1016/S0306-4522(96)00605-7

[44] Thompson, R.J., Doran, J.F., Jackson, P., Dhillon, A.P., Rode, J. (1983): PGP 9.5 - a new marker for vertebrate neurons and neuroendocrine cells. Brain Research 278 (1-2): 224-228. doi: 10.1016/0006-8993(83)90241-X

[45] Wedel, T., Roblick, U., Gleiss, J., Schiedeck, T., Bruch, H.P., Kühnel, W., KRAMMER, H.J. (1999): Organization of the enteric nervous system in the human colon demonstrated by wholemount immunohistochemistry with special reference to the submucous plexus. Annals of Anatomy 181 (4): 327-337.

doi: 10.1016/S0940-9602(99)80122-8

[46] Zanoni, J.N., DE MiRanda Neto, M.H., Bazotte, R.B., DE SouZA., R.R. (1997): Morphological and quantitative analysis of the neurons of the myenteric plexus of the cecum of streptozotocin-induced diabetic rats. Arquivos de Neuro-Psiquiatria 55 (4): 696-702. doi: 10.1590/S0004-282X1997000500004 